Article

\title{
Synthesis of TiFe Hydrogen Absorbing Alloys Prepared by Mechanical Alloying and SPS Treatment
}

\author{
Tohru Nobuki ${ }^{1,2, *}$, Taro Moriya ${ }^{1}$, Minoru Hatate ${ }^{1}$, Jean-Claude Crivello ${ }^{2}$, Fermin Cuevas ${ }^{2}$ and \\ Jean-Marc Joubert ${ }^{2}$ \\ 1 Department of Mechanical Engineering, Faculty of Engineering, KINDAI University, 1 Takaya-Umenobe, \\ Higashi-Hiroshima City 739-2115, Japan; 1633850008t@hiro.kindai.ac.jp (T.M.); \\ hatate@hiro.kindai.ac.jp (M.H.) \\ 2 Université Paris Est, ICMPE (UMR 7182), CNRS, UPEC, F-94320 Thiais, France; \\ crivello@icmpe.cnrs.fr (J.-C.C.); fermin.cuevas@icmpe.cnrs.fr (F.C.); joubert@icmpe.cnrs.fr (J.-M.J.) \\ * Correspondence: nobuki@hiro.kindai.ac.jp; Tel.: +88-82-434-7384
}

Received: 13 February 2018; Accepted: 9 April 2018; Published: 13 April 2018

check for updates

\begin{abstract}
This study aims to clarify the influence of the Spark Plasma Sintering (SPS) method on structural morphology, mechanical properties and also functional characteristics, such as hydrogen absorbing properties, for titanium-iron intermetallic compounds. We could synthesize B2-TiFe phase using mechanical alloying (MA) during $3 \mathrm{~h}$ and SPS treatment of $5 \mathrm{~min}$ at $500-1000{ }^{\circ} \mathrm{C}$, which was confirmed by XRD and Electron Probe Microanalyzer (EPMA) measurements. In addition, the synthesized TiFe intermetallic compound has been found to absorb hydrogen with high kinetics in both high pressure Differential Scanning Calorimetry (DSC) and Pressure-Composition-Temperature (PCT) measurements. Therefore, we have successfully developed TiFe alloy in bulk form from initial raw powders by using a combination of short period mechanical alloying and SPS heat treatment. This combined route enhances the potential of the SPS method to synthesize new materials.
\end{abstract}

Keywords: titanium iron; intermetallic compounds; hydrogen storage materials; mechanical alloying; spark plasma sintering; high pressure DSC measurement

\section{Introduction}

The hydrogenation properties of Titanium-Iron compound, a typical AB-type alloy with B2 structural prototype, were first determined by Reilly in 1974 [1-3]. This alloy presents many advantages, such as high cost performance and abundance in resources, moderate conditions for hydrogenation and dehydrogenation, and relatively large hydrogen storage of 1.8 mass \% [4]. However, the widespread use of TiFe intermetallic compound is hampered by the necessity to perform a rigorous activation treatment. Indeed, it requires a cyclic procedure of heating up to $673 \mathrm{~K}$ in a vacuum, cooling down to room temperature, and pressurizing hydrogen to up to $4 \mathrm{MPa}$ [5]. This procedure must be repeated over ten times to complete its full activation. This treatment of TiFe has been improved by many groups [5,6].

Mechanical alloying (MA), a well-known technique of solid-state synthesis to attain various equilibrium and non-equilibrium phases, is helpful to overcome these activation difficulties $[7,8]$. The synthesized phases have nano-crystalline microstructure and extended compositional range, compared to known equilibrium diagrams. The advantages of MA are important for many applications, in particular for reversible hydrogen storage materials. Additionally, Spark Plasma Sintering (SPS) treatment is a useful technique for the synthesisis of non-equilibrium materials, including for the fabrication of hydrogen absorbing materials [9]. Compared to the conventional powder metallurgy routes for fabrication of dense metals by hot pressing, the SPS is known as an excellent way to achieve 
rapid consolidation at lower temperatures. Employing a short sintering process is helpful when a fine grained microstructure is required [10], and it is expected to be an easy and fast process for synthesizing TiFe compounds and promoting practical applications [9,11,12]. However, only a few studies dealing with the synthesis of TiFe alloys by combined MA and SPS treatment have been reported, and its hydrogenation properties have hardly been investigated at all [12].

In this study, we have investigated the combination of MA and SPS treatments for the synthesis of TiFe intermetallic compound. Also, its hydrogenation properties have been evaluated by Differential Scanning Calorimetry (DSC) under hydrogen pressure and Pressure-Composition-Temperature (PCT) measurements.

\section{Materials and Methods}

High-purity powders of $\mathrm{Ti}(>99.5 \%)$ and $\mathrm{Fe}(>99.9 \%)$ were purchased from Kojundo Chemical Laboratory, Co. Ltd., Sakado, Japan. They had average particle sizes $(d)$ of about $90<d<180 \mu \mathrm{m}$ and $d<55 \mu \mathrm{m}$, for Ti and Fe respectively. Approximately $3 \mathrm{~g}$ of metal mixture was mechanically milled to obtain B2-TiFe intermetallic compound by ball milling under an Ar gas atmosphere. Thirty stainless steel balls $10 \mathrm{~mm}$ in diameter were used. The milling vial had an inner volume of $280 \mathrm{cc}$ and was made of stainless steel. The mechanical alloying time was varied from $3 \mathrm{~h}$ to $24 \mathrm{~h}$ with $60 \mathrm{~Hz}$ in radial speed, using an oscillatory home-made milling device. The composition of the metal mixture was varied from 50-60 at \% Ti.

Synthesized ball-milled powders underwent heat treatments. These were carried out in a furnace under vacuum for $30 \mathrm{~min}$ at several desired temperatures, by using $1 \mathrm{~g}$ of sample weight. Alternatively, as-milled samples were sintered using a SPS (Model: PLASMAN, S. S. Alloy, Higashi-Hiroshima, Japan) with pulsed DC voltage. The applied load was $10 \mathrm{kN}$ with a holding time of 5 min at the maximum adopted temperature of $1000{ }^{\circ} \mathrm{C}$. As-milled powders were loaded into a graphite die and, in order to achieve a more homogeneous temperature distribution, a graphite sheet was placed between the die and the punch. The bulk cylindrical samples obtained from the SPS process were $5 \mathrm{~mm}$ high and $20 \mathrm{~mm}$ in diameter. Their density was measured with a pycnometer under Helium gas (Model: Quantachrome Instruments, Ultrapyc1200e, Boynton Beach, FL, USA).

A scanning electron microscope (Model: S-4800 field emission SEM, Hitachi, Tokyo, Japan) was used to record images and determine powder particle size. For the mean particle sizes after mechanical alloying or after heat treatment, the image analysis software 'ImageJ' (Free software, NIH, Bethesda, MD, USA) was used and the mean diameter, and standard deviations were provided from a random selection of 100 particles for each SEM photo. For more accurate elemental analysis, an Electron Probe Micro Analyzer (EPMA), operating at $15 \mathrm{kV}$ and $100 \mathrm{nA}$ (Model: EPMA 1620H, CeB 6 tip emission, Shimadzu, Tokyo, Japan) was used. The phase identification of powder samples was carried out using X-ray diffraction (XRD) analysis (Model: Multi Flex, Rigaku, Tokyo, Japan) with Cu K $\alpha$ radiation (40 kV and $40 \mathrm{~mA}$ ). Hydrogenation properties were measured with a differential scanning calorimeter (DSC) (Model: DSC8230HP, Rigaku, Japan) under hydrogen at a pressure of $5 \mathrm{MPa}$. The sample powders were contained in open aluminum pans. The heating rate was $2{ }^{\circ} \mathrm{C} / \mathrm{min}$. Hydrogen absorption was also measured using a homemade Sieverts apparatus dedicated to PCT measurements.

\section{Results and Discussion}

\subsection{Synthesis of TiFe Phase}

Figure 1 shows the SEM images of powder mixtures prepared by mechanical alloying for 3 to $24 \mathrm{~h}$. This figure shows that the particle size becomes smaller with increasing MA time. After $3 \mathrm{~h}$, the mean particle size is about $10 \mu \mathrm{m}$, and some particles remain facetted keeping the initial aspect of the powder. Rounded surfaces are a hint for intimate mixture by cold-working between initial Ti and Fe powders, as a preliminary step for the formation of Ti-Fe alloys. After $6 \mathrm{~h}$, facetted particles are no longer observed, indicating that the process of alloying has started. After $24 \mathrm{~h}$, the mean particle size is 
comprised between 3 and $8 \mu \mathrm{m}$. No significant difference in powder morphology is observed between the different compositions.

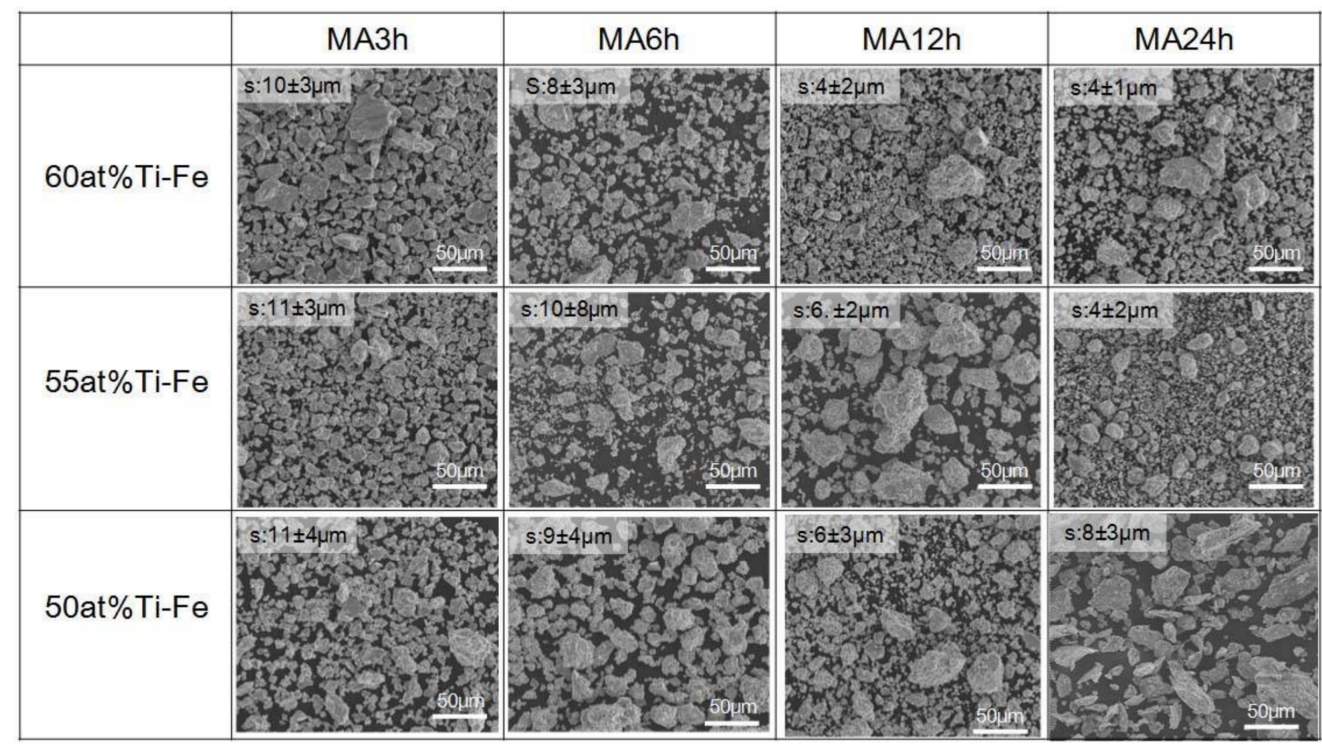

Figure 1. SEM images of mechanical alloying (MA) samples with different Ti-contents and milling time (inset values; s: mean particle size).

Figure 2 shows the XRD measurements as a function of MA time and Ti composition. $3 \mathrm{~h}$ are not sufficient to achieve TiFe synthesis. We obtained $\mathrm{Ti}_{2} \mathrm{Fe}$ and $\mathrm{TiFe}_{2}$ intermetallics, instead. Between 6 and $12 \mathrm{~h}$ the formation of B2-TiFe phase is observed with a higher crystallinity for a 60 at \% Ti sample. However, for longer times such as $24 \mathrm{~h}$, the peaks of $\mathrm{C} 14$ structure corresponding to $\mathrm{TiFe}_{2}$ phase represent the main contribution. This behavior can probably be explained by Fe contamination from the vial and the balls.

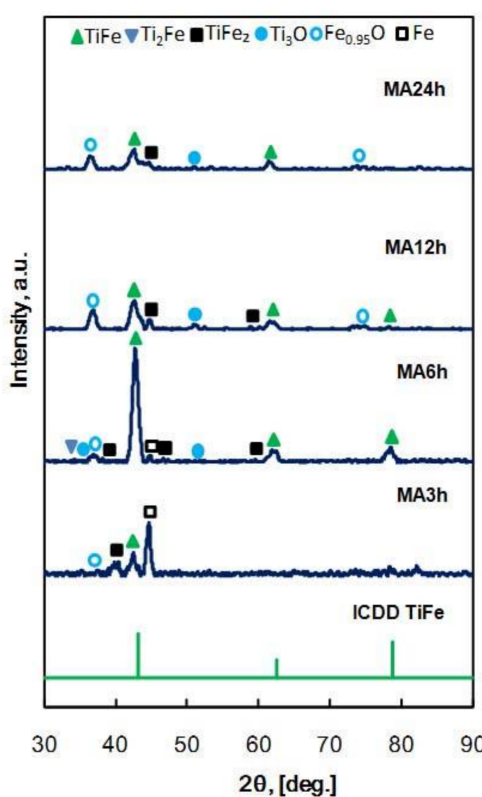

(a)

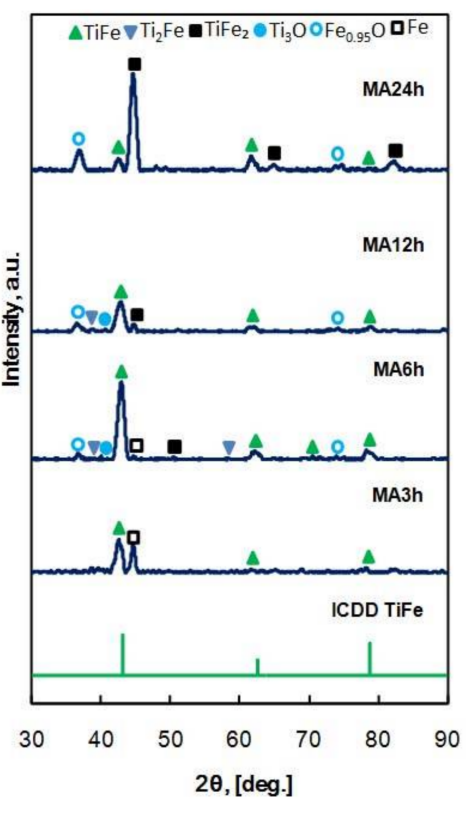

(b)

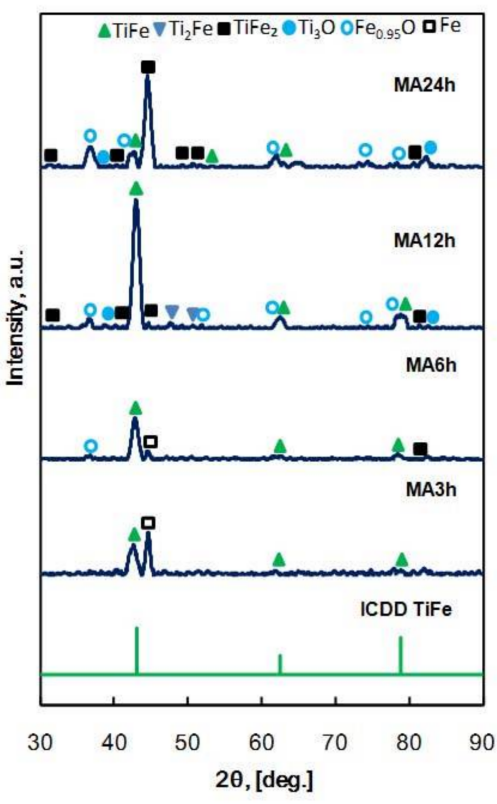

(c)

Figure 2. XRD patterns of MA samples with different Ti-contents and milling time. (a) 60 at \% Ti-Fe; (b) 55 at \% Ti-Fe; (c) 50 at \% Ti-Fe. 
Then, in order to complete TiFe phase formation, we carried out a heat treatment for $3 \mathrm{~h}$ of the MA samples, as reported in Ref. [13-15]. Figure 3 shows the influence of heat treatment temperature and Ti composition on the obtained particle size and morphology. With the annealing treatment, the mean particle size increases with temperature. Obtained particle size after annealing at $600{ }^{\circ} \mathrm{C}$ is about $20 \mu \mathrm{m}$. As a function of temperature, the surface morphology evolves, showing growth reaction between particles through neck-shaped region, particularly after treatment at $600{ }^{\circ} \mathrm{C}$.

\begin{tabular}{|c|c|c|c|c|}
\hline MA3h & As MA & $400^{\circ} \mathrm{C}$ & $500^{\circ} \mathrm{C}$ & $600^{\circ} \mathrm{C}$ \\
\hline 60at $\% \mathrm{Ti}-\mathrm{Fe}$ &  & 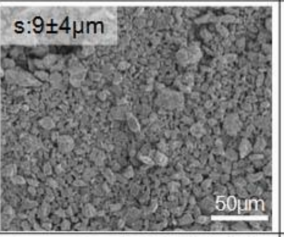 & 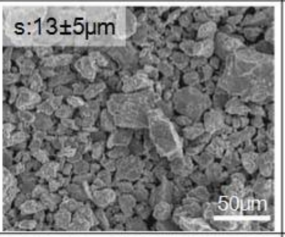 &  \\
\hline 55at\%Ti-Fe & 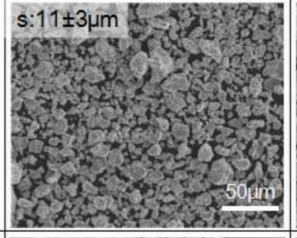 & 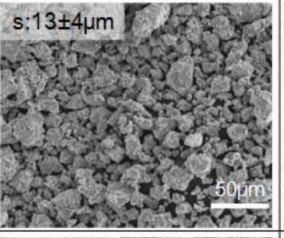 & 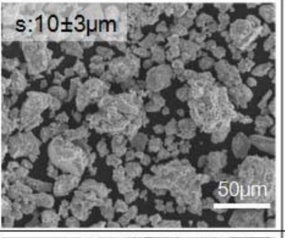 & 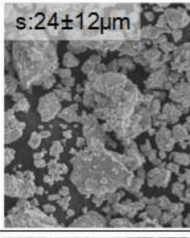 \\
\hline 50at\%Ti-Fe & 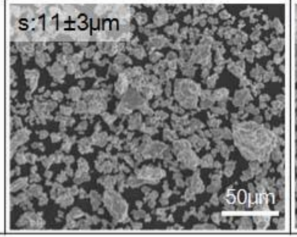 & 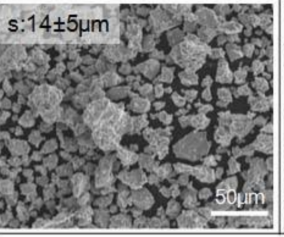 & 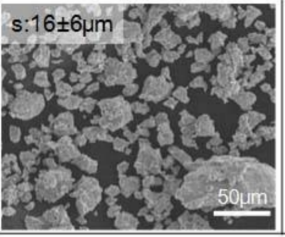 & 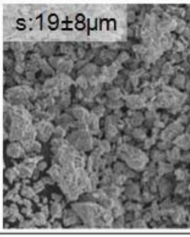 \\
\hline
\end{tabular}

Figure 3. SEM images of $3 \mathrm{~h}$ MA samples with different Ti-contents after heat treatment at several temperatures.

The XRD patterns of these heat treated samples after $3 \mathrm{~h}$ MA are shown in Figure 4 . The peaks corresponding to the TiFe phase increase with the annealing temperature. This means that both the formation and crystallization of the TiFe phase could be enhanced by an additional heat treatment in vacuum furnace, as in the case of $\mathrm{Mg}$-Al compounds [16]. Additionally, we noted that the samples with higher Ti content show sharper diffraction peaks.

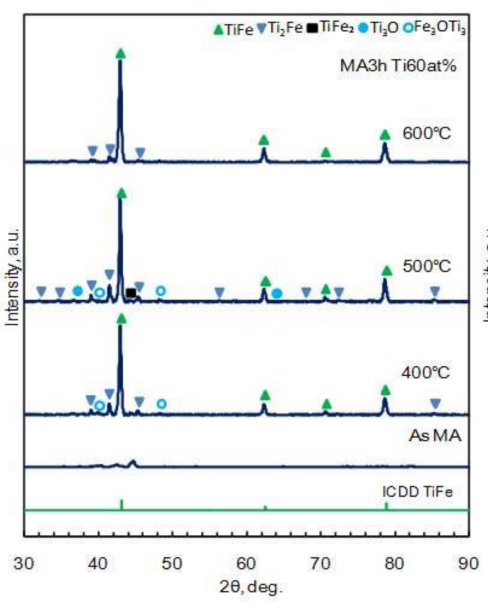

(a)

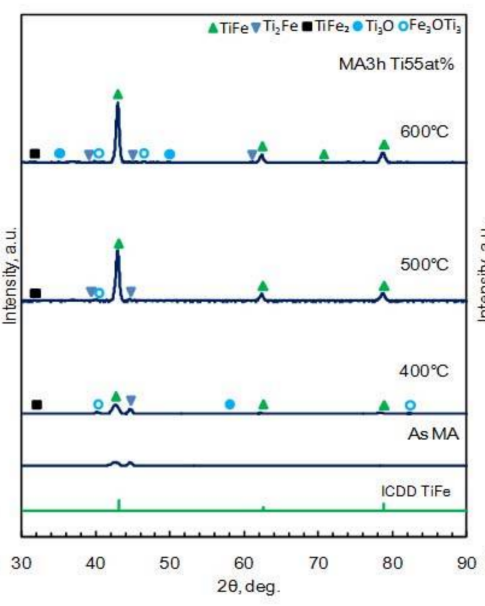

(b)

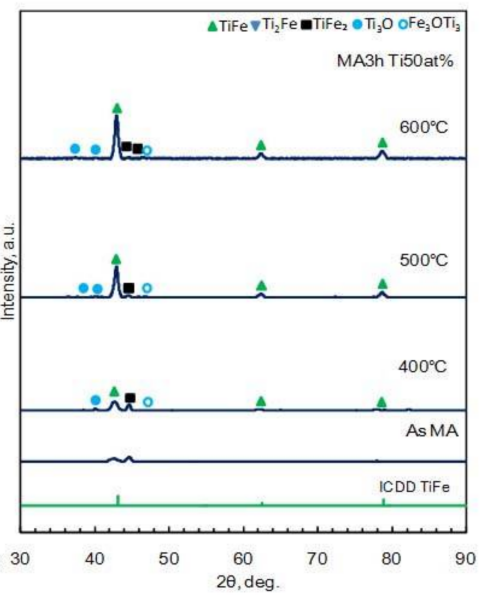

(c)

Figure 4. XRD patterns of $3 \mathrm{~h}$ MA samples with different Ti-contents after heat treatment at several temperatures. (a) 60 at \% Ti-Fe; (b) 55 at \% Ti-Fe; (c) 50 at \% Ti-Fe. 
As an alternative to the classical annealing route, we have investigated the effect of SPS treatment on Ti-Fe powders milled for $3 \mathrm{~h}$. Figure 5 shows SEM images of the sample surface morphology for the various investigated SPS temperatures; the results of micro-Vickers hardness tests are expressed in the upper left corner of each picture. Independently of the Ti composition, the morphology becomes more uniform with an increase in SPS treatment temperature, due to densification. Some porosity is observed in SPS samples treated at low temperatures. The hardness of SPS treated samples is somewhat higher than values reported in the literature for TiFe phase (350 HV) [17-19]. This difference is attributed to the large strains induced by mechanical milling and the compression stress induced by SPS treatment [20].

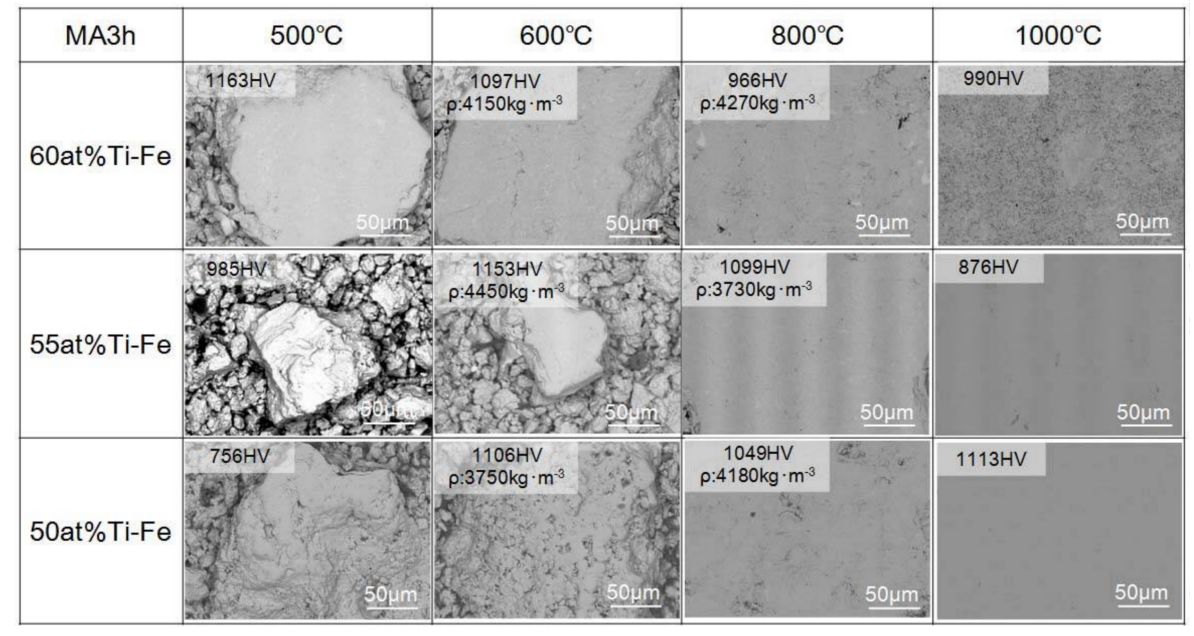

Figure 5. SEM images and micro-Vickers hardness test results and/or density measurement results of surfaces of SPS treated samples after polishing.

Density values vary from 3730 to $4450 \mathrm{~kg} \cdot \mathrm{m}^{-3}$. This is between $57-68 \%$ of the reported density of bulk-TiFe $\left(6550 \mathrm{~kg} \cdot \mathrm{m}^{-3}\right)$ [7]. This result suggests that the SPS sample involves around $30 \%$ of closed porosity.

Figure 6 shows the XRD measurement results obtained from SPS treated samples. The SPS temperature seems to affect the nature of the present phases. Indeed, the SPS treatment improves the crystallinity of TiFe phase, but induces the formation of secondary phases for temperatures above $800{ }^{\circ} \mathrm{C}$. Among the different samples, the one with 60 at \% Ti SPS treated at $600{ }^{\circ} \mathrm{C}$ is very well crystallized. At higher temperatures, the metastable cubic $\mathrm{Ti}_{2} \mathrm{Fe}$ phase grows and shows diffraction peaks higher than those from the TiFe desired phase.

Figure 7 shows diffraction patterns of 60 at \% Ti-Fe alloy annealed at $600{ }^{\circ} \mathrm{C}$ and 50 at \% Ti-Fe alloy SPS treated at $800^{\circ} \mathrm{C}$. From the Rietveld analysis, we identified phase composition, abundance and lattice parameters. For a 60 at \% Ti-Fe alloy annealed at $600{ }^{\circ} \mathrm{C}$, the main phase is TiFe $(89 \mathrm{wt} \%)$, with a lattice parameter $a=0.2978 \mathrm{~nm}$. In addition, three minor phases were observed: $\mathrm{Ti}_{2} \mathrm{Fe}(6 \mathrm{wt} \%)$, $\mathrm{Ti}_{3} \mathrm{Fe}_{3} \mathrm{O}$ (3 wt \%, stabilized by oxygen) and $\mathrm{Ti}_{3} \mathrm{O}$ (3 wt \%). On the other hand, for the 50 at $\%$ TiFe alloy SPS treated at $800{ }^{\circ} \mathrm{C}$, the content of TiFe phase is lower $(74 \mathrm{wt} \%)$, and only two minor phases are detected: $\mathrm{TiFe}_{2}(12 \mathrm{wt} \%)$ and $\mathrm{Ti}_{3} \mathrm{Fe}_{3} \mathrm{O}(14 \mathrm{wt} \%)$.

Figure 8 gathers the graphical output Rietveld analysis for the $3 \mathrm{~h} \mathrm{MA}$, heat-treated and SPS treated for the different titanium contents. Phase composition, amount, and lattice parameters for the main TiFe phase are displayed. Some unidentified XRD peaks exist in MA diffraction patterns, whereas all phases were identified in heat treated and SPS patterns. For MA samples, the lattice parameter of the cubic TiFe phase $(a=0.300 \mathrm{~nm})$ is larger compared to bulk TiFe $(a=0.295 \mathrm{~nm})$ [21]. After heat treatment, the lattice parameter shrinks $(a=0.298 \mathrm{~nm})$ because of stress /strain relief. For SPS treated samples, the lattice parameter is similar to that of heat treated samples. 


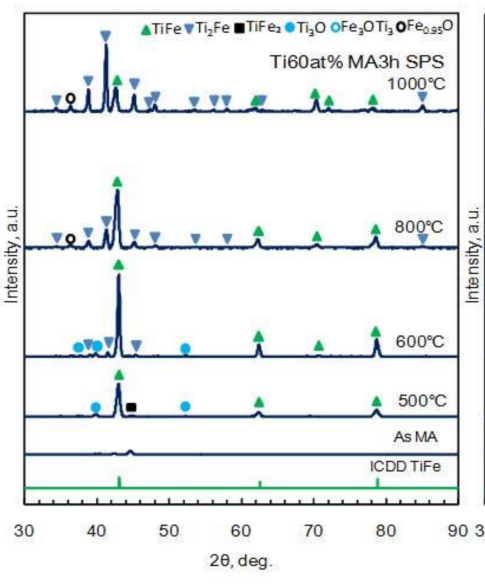

(a)

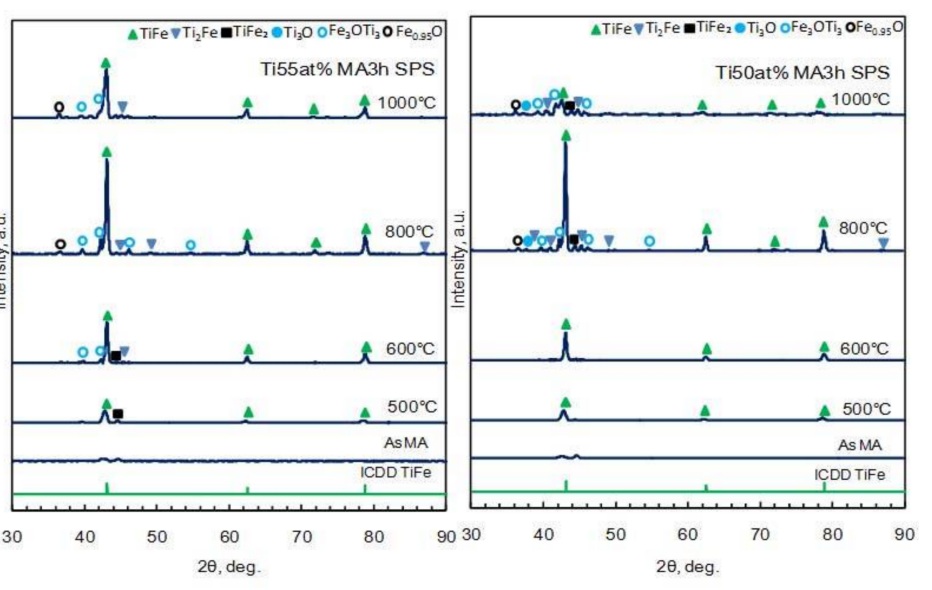

(b)

(c)

Figure 6. XRD patterns of 3 h MA samples undergoing different SPS treatments. (a) 60 at \% Ti-Fe; (b) 55 at \% Ti-Fe; (c) 50 at \% Ti-Fe.

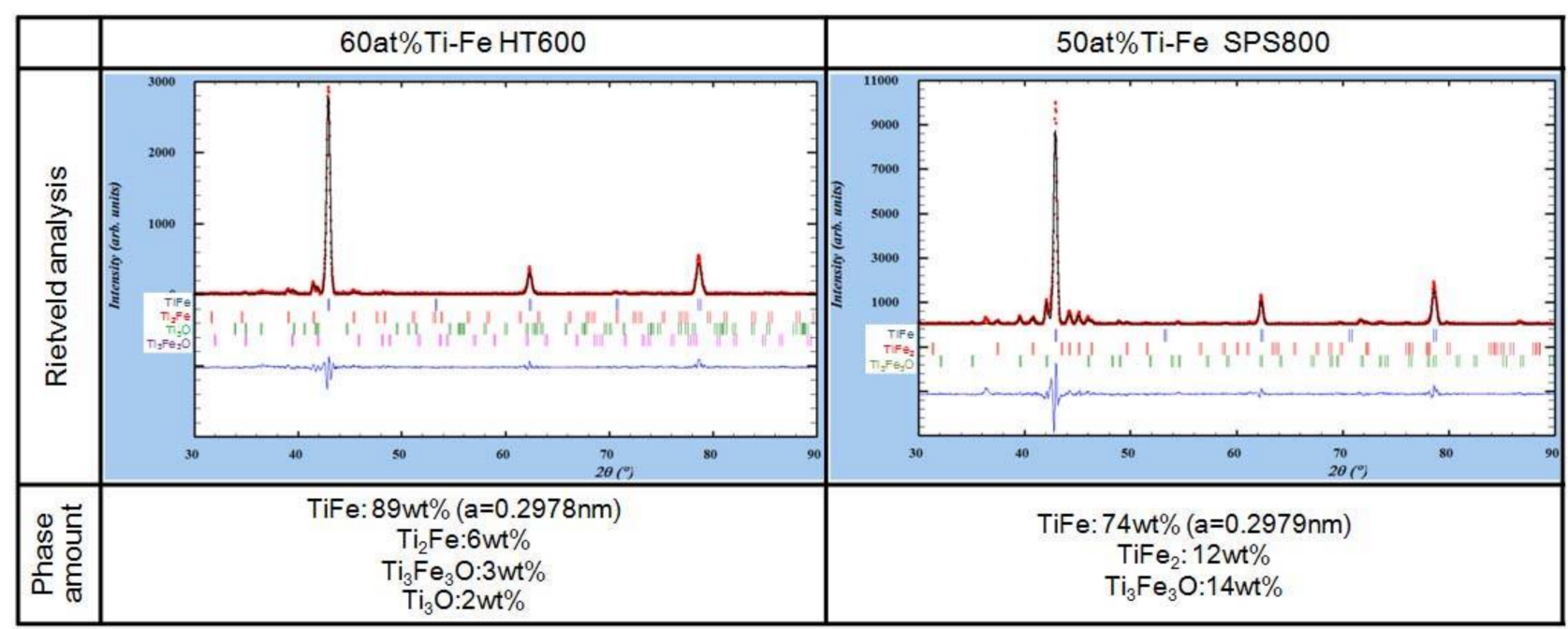

Figure 7. Rietveld analysis results for $3 \mathrm{~h}$ MA samples comparing annealing and SPS treatments. 


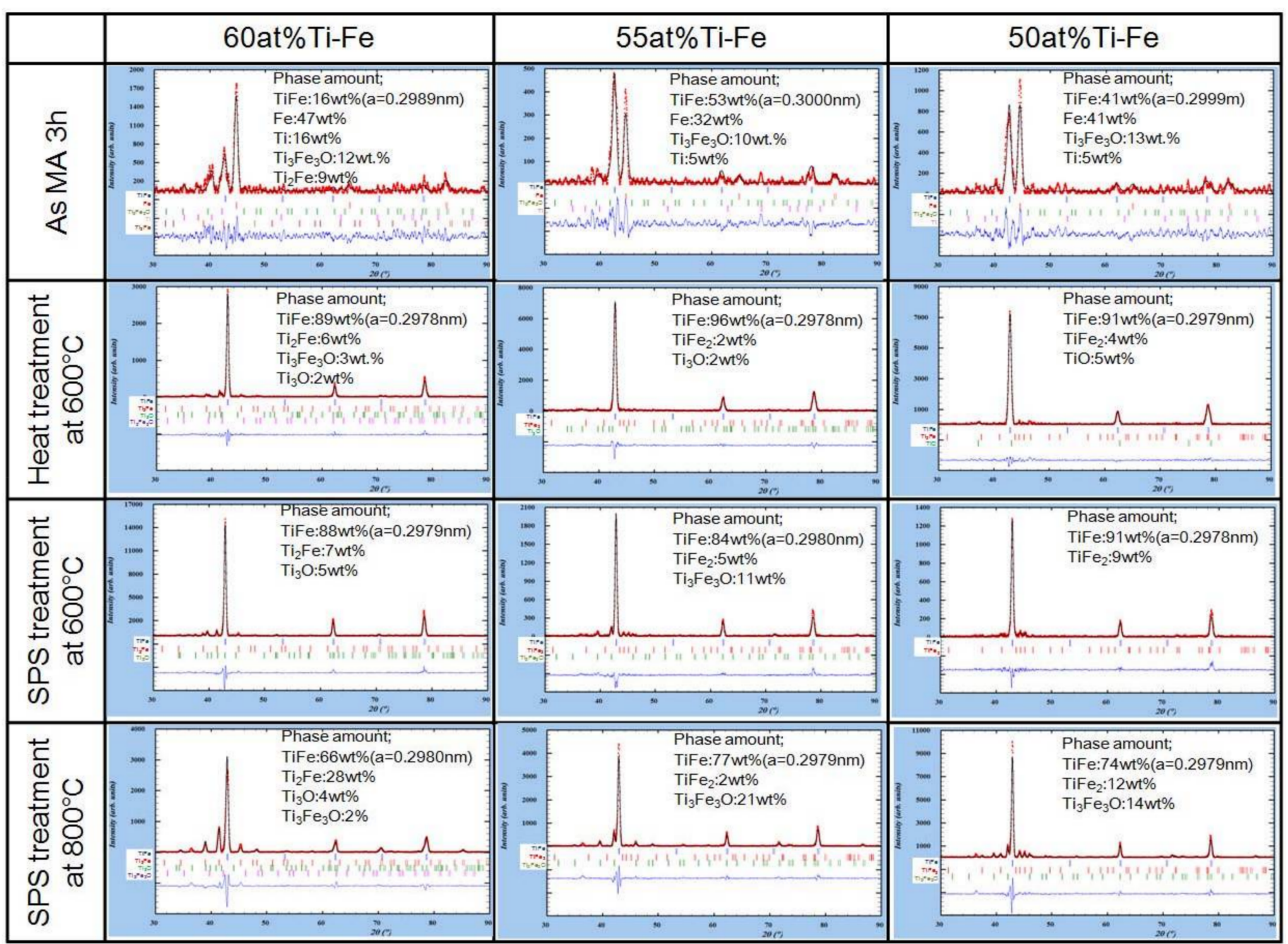

Figure 8. Rietveld analysis result for various Ti-Fe composition samples (Inset value; a: lattice parameter of TiFe phase, phase abundance). 
Figure 9 shows the EPMA elemental mapping $\left(\mathrm{Fe}_{-} \mathrm{K} \alpha\right)$ for $3 \mathrm{~h}$ MA samples of various Ti-Fe after different SPS dwell temperatures. Below $600{ }^{\circ} \mathrm{C}$, the Fe content is spatially inhomogeneous. However, for temperatures above $800{ }^{\circ} \mathrm{C}$, alloys are much more homogeneous with concentration for the main phase approaching 50 at \% Fe (green color). This result shows that SPS is a suitable technique to synthesize TiFe phase.

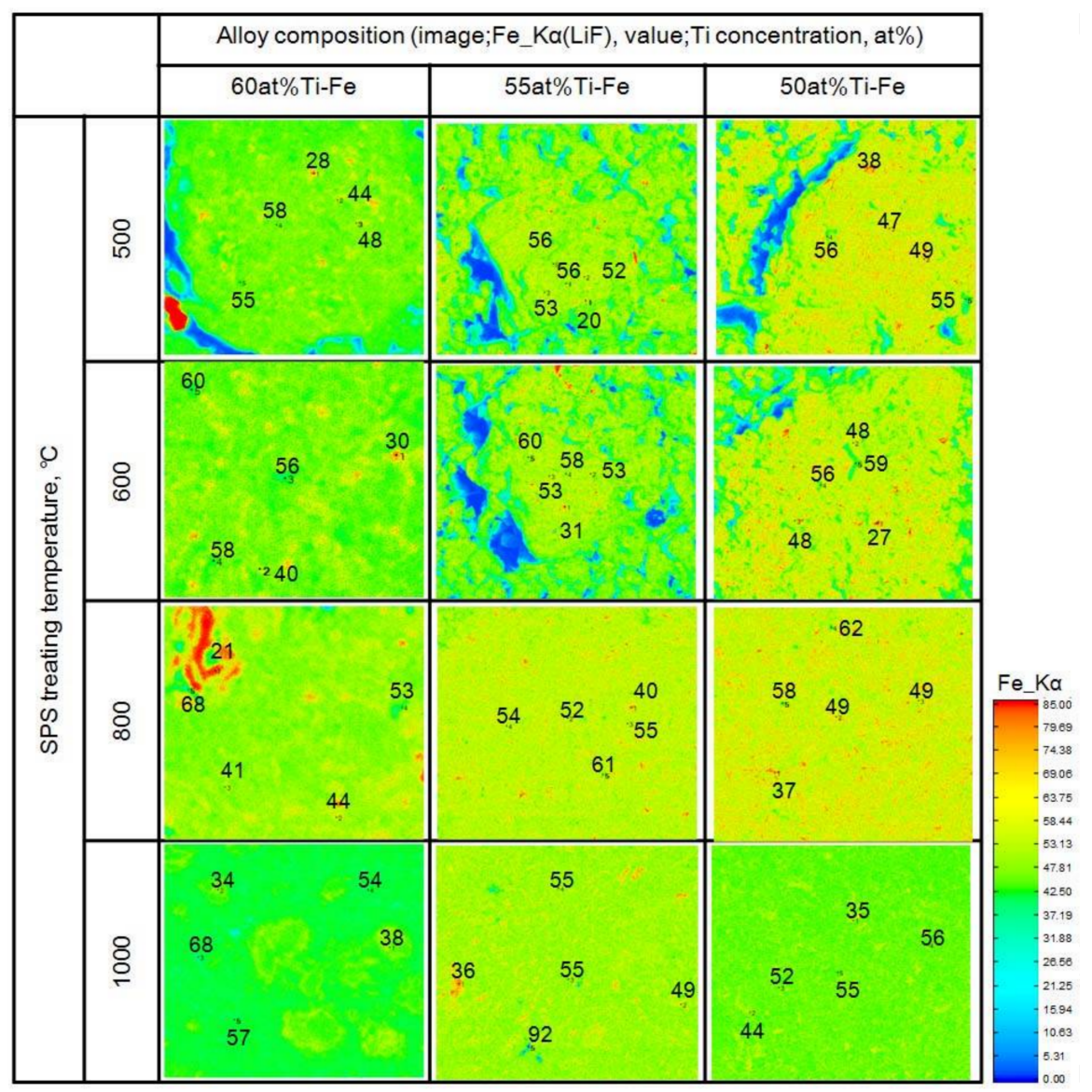

Figure 9. EPMA elemental mapping for Fe_K $\alpha$ of SPS treated samples. Numbers in the micrographs stand for Ti concentration at specific sample locations (at \%).

\subsection{Hydrogenation Properties}

Following the synthesis of the TiFe phase, investigations about hydrogenation properties have been carried out by using a high pressure-DSC apparatus. The DSC measurements were done under a $\mathrm{H}_{2}$ pressure of $5 \mathrm{MPa}$ during heating and cooling runs. Various Ti-Fe alloys were studied: a commercial product (purchased from Kojundo Chemical Laboratory, Co. Ltd., Japan, $d<100 \mu \mathrm{m}$ ), and samples synthesized by $3 \mathrm{~h} \mathrm{MA}$ and subsequent heat treatment at $600{ }^{\circ} \mathrm{C}$ or SPS treatment at $800^{\circ} \mathrm{C}$. Figure 10 shows the endo/exothermic peaks according to desorption/absorption hydrogen reactions. For the synthesized alloy, the heating cycle showed an endothermic peak at around $120{ }^{\circ} \mathrm{C}$, which was attributed to hydrogen desorption on this cycle. On the cooling cycle, the small exothermic peak at around $50{ }^{\circ} \mathrm{C}$ shows that some hydrogen uptake occurs. The sample prepared by vacuum furnace shows higher endo/exothermic peak temperatures. This is caused by some oxidation during this complex process. The reaction temperatures corresponding to these peaks are not different between commercial and our own synthesized TiFe alloy materials. Moreover, the hydrogen absorption characteristics of these alloys showed a good repeatability during the second DSC run, showing a fully reversible reaction, as discussed in literature [13,22,23]. Our SPS $800{ }^{\circ} \mathrm{C}$ treated sample was also measured on a Sieverts apparatus. It absorbed without any activation, contrary to most previous 
reports. Compared with the literature, the SPS sample presented good kinetics in both hydrogen absorption and desorption. The elapsed time for $90 \%$ of full absorption was $180 \mathrm{~s}$ under $5 \mathrm{MPa}$ of Hydrogen at $40{ }^{\circ} \mathrm{C}$. This hydrogen absorbing/desorbing kinetics is similar to that of previous reports $[3,4,12,24]$. From the PCT measurement at $40{ }^{\circ} \mathrm{C}$, the sample could absorb 0.75 mass $\%$ reversibly, and hydrogen plateau pressure is $2.5 \mathrm{MPa}$ for absorption and $0.7 \mathrm{MPa}$ for desorption. This represents a larger hysteresis compared with Ref. [3], which could be explained by the high hardness of the material [25]. The smaller capacity compared to commercial TiFe (1.8 mass \%) can be partially explained both by the phase abundance (74 wt \%) and this higher absorption pressure.

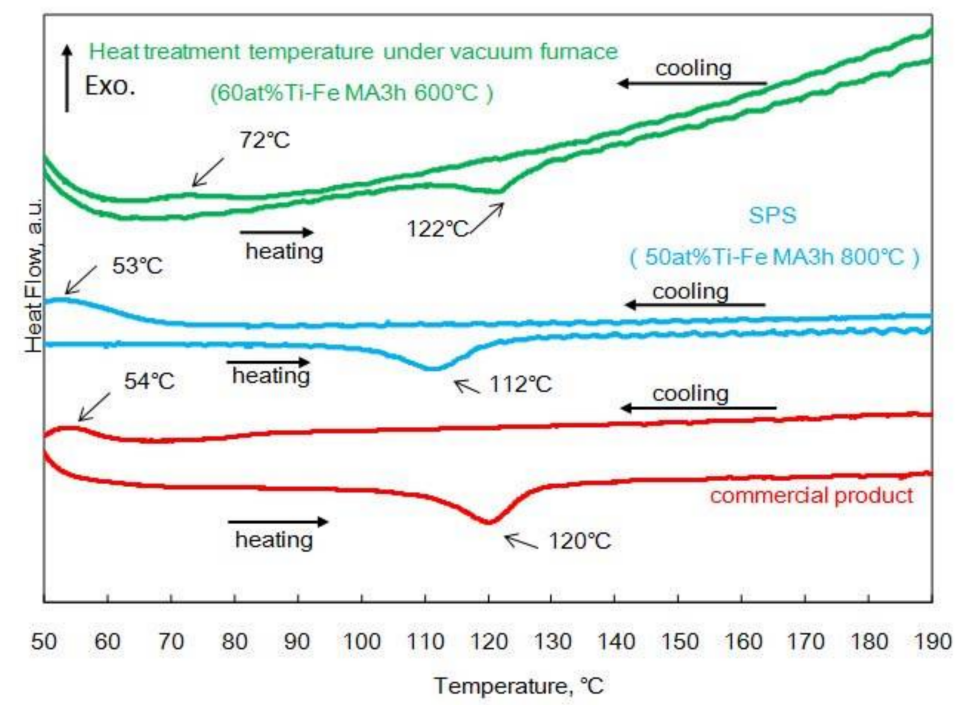

Figure 10. DSC measurement curves of various Ti-Fe alloys.

\section{Conclusions}

We have synthesized the B2-TiFe intermetallic compound, a well-known phase that could absorb/desorb hydrogen, by short time mechanical alloying (3 h), followed by a SPS treatment.

The results in this study are summarized as follows:

1. The B2-TiFe intermetallic phase is obtained from 50 at $\%$ to 60 at $\%$ Ti composition after $6 \mathrm{~h}$ of mechanical alloying under an atmosphere of Ar gas. The TiFe phase is well crystallized in the sample with 60 at \% Ti composition.

2. The particle size is about $10 \mu \mathrm{m}$ after $3 \mathrm{~h}$ of mechanical alloying, and does not depend on Ti composition.

3. With a short MA period ( $3 \mathrm{~h}$ ), additional heat treatment at $600{ }^{\circ} \mathrm{C}$ forms the TiFe phase with minor amount of secondary phases. For instance, $96 \mathrm{wt} \%$ of TiFe phase is formed for 55 at $\% \mathrm{Ti}$.

4. The TiFe intermetallic compound could be formed using 50 at $\%$ Ti-Fe powder mixtures, prepared by $3 \mathrm{~h}$ of MA after $5 \mathrm{~min}$ of SPS treatment at temperatures higher than $800{ }^{\circ} \mathrm{C}$. The phase abundance of 50 at \% Ti-Fe prepared by $3 \mathrm{~h}$ of MA and SPS at $800{ }^{\circ} \mathrm{C}$ were $74 \mathrm{wt} \%$ of TiFe phase, 12 wt $\%$ of $\mathrm{TiFe}_{2}$ and 14 wt $\%$ of $\mathrm{Ti}_{3} \mathrm{Fe}_{3} \mathrm{O}$ phase estimated by Rietveld analysis.

5. Synthesized Ti-Fe alloy prepared by MA + SPS treatment shows hardness over $1000 \mathrm{HV}$, because of the huge strain induced during MA and compaction stress in SPS treatment.

6. Synthesized TiFe intermetallic phase by MA + SPS could reversibly absorb hydrogen with the same hydrogenation kinetics as a commercial TiFe, without requiring any complicated hydrogen activation treatments. Compared to commercial TiFe alloy, large hysteresis in hydrogen equilibrium pressure was observed, which likely relates to the high hardness of the synthesized alloy. 
We can therefore conclude that mechanical alloying combined with SPS is an interesting technique for the synthesis of hydrogen storage materials in general, and TiFe in particular.

As a future work, we have planned to measure in detail the hydrogenation properties (activation, thermodynamic and kinetics) of all SPS treated samples, to understand the influence of SPS preparation conditions on the hydrogenation properties of TiFe phase.

Author Contributions: Tohru Nobuki, Taro Moriya and Minoru Hatate have synthesized materials and measuring, estimation \& discussions about experimental data. Some calculations and discussions for FullProf were made by Jean-Marc Joubert. Determination of hydrogenation properties in Sieverts' device were made by Fermin Cuevas and additional image analysis and discussions were made with Jean-Claude Crivello. All authors have contributed to the discussions for manuscript and have approved the final version.

Conflicts of Interest: The authors declare no conflict of interest.

\section{References}

1. Hoffman, K.C.; Reilly, J.J.; Salzano, F.J.; Waide, C.H.; Wiswall, R.H.; Winsche, W.E. Metal hydride storage for mobile and stationary applications. Int. J. Hydrogen Energy 1976, 1, 133-151. [CrossRef]

2. Reilly, J.J.; Johnson, J.R.; Reidinger, F.; Lynch, J.F.; Tanaka, J.; Wiswall, R.H. Lattice expansion as a measure of surface segregation and the solubility of hydrogen in $\alpha-\mathrm{FeTiH}_{x}$. J. Less Common Met. 1980, 73, 175-182. [CrossRef]

3. Reilly, J.J.; Wiswall, R.H., Jr. Formation and properties of iron titanium hydride. Inorg. Chem. 1974, 13, 218-222. [CrossRef]

4. Li, C.H.; He, J.; Zhang, Z.; Yang, B.; Leng, H.Y.; Lu, X.G.; Li, Z.L.; Wu, Z.; Wang, H.B. Preparation of TiFe based alloys melted by $\mathrm{CaO}$ crucible and its hydrogen storage properties. J. Alloys Compd. 2015, 618, 679-684. [CrossRef]

5. Wakabayashi, R.; Sasaki, S.; Okinaka, N.; Akiyama, T. Self-ignition combustion synthesis of $\mathrm{TiFe}_{1-x} \mathrm{Mn}_{x}$ hydrogen storage alloy. Int. J. Hydrogen Energy 2009, 34, 9122-9127. [CrossRef]

6. Miyamura, H.; Takada, M.; Hirose, K.; Kikuchi, S. Metal hydride electrodes using titanium-iron-based alloys. J. Alloys Compd. 2003, 356, 755-758. [CrossRef]

7. Zadorozhnyy, V.; Klyamkin, S.; Zadorozhnyy, M.; Bermesheva, O.; Kaloshkin, S. Hydrogen storage nanocrystalline TiFe intermetallic compound: Synthesis by mechanical alloying and compacting. Int. J. Hydrogen Energy 2012, 37, 17131-17136. [CrossRef]

8. Tsuchiya, T.; Yasuda, N.; Sasaki, S.; Okinaka, N.; Akiyama, T. Combustion synthesis of TiFe-based hydrogen storage alloy from titanium oxide and iron. Int. J. Hydrogen Energy 2013, 38, 6681-6686. [CrossRef]

9. Nobuki, T.; Kanekawa, S.; Hatate, M.; Takenaka, H.; Kuji, T. Development of Mg based hydrogen absorbing alloys prepared by mechanical alloying. J. Alloys Compd. 2013, 580, S259-S263. [CrossRef]

10. Li, B.; Liu, Y.; Cao, H.; He, L.; Li, J. Rapid synthesis of $\mathrm{TiB}_{2} /$ Fe composite in situ by spark plasma sintering. J. Mater. Sci. 2009, 44, 3909-3912. [CrossRef]

11. Asl, M.S.; Namini, A.S.; Motallebzadeh, A.; Azadbeh, M. Effects of sintering temperature on microstructure and mechanical properties of spark plasma sintered titanium. Mater. Chem. Phys. 2018, 203, 266-273. [CrossRef]

12. Hong, S.H.; Song, M.Y. Fabrication of Fe-Ti alloys by pulsed current-assisted reaction from Iron, manganese and titanium oxide or titanium hydride. Met. Mater. Int. 2013, 19, 895-899. [CrossRef]

13. Ohno, T. Spark plasma sintering of mechanically milled pure Titanium with stearic acid additive. J. Jpn. Soc. Powder Powder Metall. 2010, 57, 327-332. (In Japanese) [CrossRef]

14. Hotta, H.; Abe, M.; Kuji, T.; Uchida, H. Synthesis of Ti-Fe alloys by mechanical alloying. J. Alloys Compd. 2007, 439, 221-226. [CrossRef]

15. Abe, M.; Honjo, T.; Kuji, T. Hydriding properties of Ti-Mg alloy with BCC structures synthesized from $\alpha$-Ti and $\beta$-Ti by ball milling. J. Jpn. Inst. Light Met. 2012, 62, 2-6. (In Japanese) [CrossRef]

16. Abe, M.; Nobuki, T.; Kuji, T. Crystallizaition beheavor of nano-crystalline $\mathrm{Mg}_{17} \mathrm{Al}_{12}$ alloy prepared by ball-milling and its hydriding properties. J. Jpn. Inst. Light Met. 2009, 59, 75-80. [CrossRef]

17. Kessler, H.D.; Rostoker, W.; Van Thyne, R.J. Titanium Phase Diagrams; WDC Technical Report 52-335; Armour Research Foundation, Illinois Institute of Technology: Chicago, IL, USA, 1953; Volume 33. 
18. Chen, H.Y.; Luo, L.M.; Zhang, J.; Zan, X.; Zhu, X.Y.; Luo, G.N.; Wu, Y.C. Investigation on W/Fe diffusion bonding using Ti foil and Ti powder interlayer by SPS. J. Nucl. Mater. 2015, 467, 566-571. [CrossRef]

19. Edalati, K.; Matsuda, J.; Iwaoka, H.; Toh, S.; Akiba, E.; Horita, Z. High-pressure torsion of TiFe intermetallics for activation of hydrogen storage at room temperature with heterogeneous nanostructure. Int. J. Hydrogen Energy 2013, 38, 4622-4627. [CrossRef]

20. Diatta, J.; Antou, G.; Pradeilles, N.; Maître, A. Numerical modeling of spark plasma sintering-Discussion on densification mechanism identification and generated porosity. J. Eur. Ceram. Soc. 2017, 37, 4849-4860. [CrossRef]

21. Toma, O.; Dzevenko, M.; Oliynyk, A.; Lomnytska, Y. The Ti-Fe-P system: Phase equilibria and structure of phases. Cent. Eur. J. Chem. 2013, 11, 1518-1526. [CrossRef]

22. Reilly, J.J.; Reidinger, F. Surface aggregates produced on activated FeTi as determined by X-ray diffraction. J. Less Common Met. 1982, 75, 145-153. [CrossRef]

23. Rusman, N.A.A.; Dahari, M. A review on the current progress of metal hydrides material for solid-state hydrogen storage applications. Int. J. Hydrogen Energy 2016, 41, 12108-12126. [CrossRef]

24. Morris, S.; Dodd, S.B.; Hall, P.J.; Mackinnon, A.J.; Berlouis, L.E.A. The effect of novel processing on hydrogen uptake in FeTi- and magnesium-based alloys. J. Alloys Compd. 1999, 293, 458-462. [CrossRef]

25. Shirasaki, K.; Tamura, T.; Kuriiwa, T.; Goto, T.; Kamegawa, A.; Takamura, H.; Okada, M. Cyclic properties of protium absorption-desorption in Ti-Cr-V alloys. Mater. Trans. 2002, 43, 1115-1119. [CrossRef]

(C) 2018 by the authors. Licensee MDPI, Basel, Switzerland. This article is an open access article distributed under the terms and conditions of the Creative Commons Attribution (CC BY) license (http:/ / creativecommons.org/licenses/by/4.0/). 